\title{
HUBUNGAN PENGETAHUAN DENGAN AKURASI PENGAMBILAN KEPUTUSAN PERAWAT DALAM PELAKSANAAN TRIAGE
}

\author{
Purwoko Sugeng Harianto ${ }^{1}$, Dian Susmarini ${ }^{2}$, Ali Haedar, ${ }^{3}$ Edi Widjajanto ${ }^{4}$ \\ ${ }^{1}$ Program Magister Keperawatan Gawat Darurat Fakultas Kedokteran Universitas Brawijaya \\ purwoko sh@yahoo.com \\ ${ }_{2}^{2}$ Staf Pengajar Magister Keperawatan Fakultas Kedokteran Universitas Brawijaya \\ ${ }^{3}$ Staf Laboratorium Emergency Medicine Fakultas Kedokteran Universitas Brawijaya \\ ${ }^{4}$ Laboratorium Patologi Klinik Fakultas Kedokteran Universitas Brawijaya
}

\begin{abstract}
Emergency Department (ED) provides nursing care for 24 hours a day. Triage is the initial activity of the nurse when a patient comes to ED. It is a process of sorting patients according to severity. Accurate triage decision has significant impacts on patient's outcomes. In fact there are many nurses who work in the EDwith insufficient knowledge and skills on triage. Knowledge and skills have relationships with the implementation of triage.In general, there are two factors that affect the accuracy of nurse decision making in the triage. The first factor are the internal factors that describe the knowledge, work experience and training of the nurses; while the second factors are the external factors that include matters relating to the working environment and workload. The desertion of internal and external factors cancause inaccurate triage decision making and indirectly may lead topossible permanent disability in patients.

The purpose of this study was to analyze the influences of internal and external factors on increasing accuracy of nurses'triage decision making at the EDin Dr. Saiful Anwar Malang PublicHospital. Correlational analytic design with cross sectional was implemented in this research. The data was collected through questionnaire and observation sheets from April 15 to May 15, 2015 to 50 respondents as the samples. The bivariate analysis used Pearson correlation. The results showed thatthere is correlation between knowledge and accuracy of decision making in the implementation of triage nurses ( $p$ value $=0.000<\alpha$ ) with a correlation coefficient of 0565.It is suggested that the hospital increase the knowledge, skills and competence of the nurses through ED nurse education and the triage officer training.
\end{abstract}

Key words: ED, knowledge, accuracy of nurses decision making, Triage. 


\begin{abstract}
ABSTRAK
Instalasi Gawat Darurat (IGD) memberikan pelayanan perawatan selama 24 jam setiap harinya. Triage merupakan aktivitas awal yang dilakukan perawat ketika pasien datang ke IGD. Triagemerupakan proses memilahpasien menurut tingkat keparahannya. Akurasi keputusan triage mempunyai dampak yang signifikan pada outcome pasien. Pada kenyataanya masih banyak perawat yang bekerja di IGD memiliki pengetahuan dan keterampilan yang kurang tentang triage.Pengetahuan dan ketrampilan mempunyai hubungan dengan pelaksanaan triage.Secara umum,terdapat dua faktor yang mempengaruhiakurasi pengambilan keputusanperawat dalam pelaksanaan triage.Faktor pertama adalah faktor internal yang menggambarkan tentang pengetahuan, pengalaman kerja dan pelatihan perawat, sedangkan faktor kedua merupakan faktor eksternal meliputi hal-hal yang berhubungan dengan lingkungan kerja dan beban kerja.Pengabaian terhadap faktor internal dan eksternal dapat menyebabkan pelaksanaan triage menjadi tidak akurat dan mengakibatkan kecacatan permanen pada pasien.

Tujuan penelitian ini adalah menganalisis hubungan pengetahuan dengan akurasi pengambilan keputusan perawat dalam pelaksanaan triage di IGD RSUD Dr. Saiful Anwar Malang. Penelitian ini menggunakan desain analitik korelasional dengan pendekatan cross sectional. Pengambilan data dilakukan tanggal 15 April sampai 15 Mei 2015 dengan jumlah sampel 50 responden.Pengambilan data menggunakan instrument lembar kuesioner dan lembar observasi.Analisis bivariat menggunakan korelasi Pearson. Hasil penelitian menunjukkan ada hubungan antara pengetahuan dengan akurasi pengambilan keputusan perawat dalam pelaksanaan triage $(p$ value $=0.000<\propto)$ dengan koefisien korelasi 0.565 . Diharapkan pihak rumah sakit dapat meningkatkan pengetahuan, keterampilan dan kompetensi perawat IGD melalui pendidikan berkelanjutan dan pelatihan triage officer.
\end{abstract}

Kata Kunci: IGD, Pengetahuani, akurasi pengambilan keputusan perawat, Triage

\section{PENDAHULUAN}

Instalasi Gawat Darurat (IGD) umumnya memberikan pelayanan perawatan pada pasien selama 24 jam setiap harinya. Jumlah kunjungan pasien ke IGD pada beberapa tahun terakhir mengalami peningkatan. Pada tahun 1994 terdapat 93 juta kunjungan dan pada tahun 2005 sebanyak 115 juta kunjungan (Tsai, C, 2009). Kunjungan pasien ini semakin meningkat tajam pada tahun 2011 dengan jumlah pasien lebih dari 131 juta (Weiss, et al, 2014). Peningkatan jumlah kunjungan ini dapat mengakibatkan pelayanan di IGD menjadi overcrowded (Van Gerven, et al. 2001, Roukema, et al. 2006, Van der Wulp, et al. 2008) dan mengganggu kualitas pelayanan (National Center for Health Statistics (U.S), 2004). Jumlah pasien yang tidak bisa diprediksi ini datang ke IGD dengan berbagai macam kondisi yang meliputi kondisi mengancam nyawa, urgensi maupun cedera atau sakit ringan.

Pasien yang datang ke IGD membutuhkan pengkajian dan evaluasi awal.Untuk melakukan evaluasi ini dibutuhkan tindakan triage.Triage merupakan aktivitas awal yang dilakukan perawat ketika pasien tiba di IGD. Triage adalah proses pengambilan keputusan untuk memprioritaskan kebutuhan dan terapi pasien di IGD berdasarkan kegawatannya. Triage didefinisikan sebagai klasifikasi keakutan pasien yang mencirikan sejauh mana kondisi pasien yang mengancam jiwa mendapatkan pengobatan (Gilboy, et al. 2005). 
Berdasarkan studi pendahuluan, IGD RSUD Dr Saiful Anwar Malang telah menerapkan model triage sejak tahun 2000. Pelaksanaan triage ini dilakukan oleh perawat terlatih dengan pedoman Protocol Singapore Patient Acuity Category Scale (SPACS). Namun, hingga saat ini belum ada evaluasi formal terhadap pelaksanaan triage, sehingga belum diketahui keakuratan pengambilan keputusannya. Jika terjadi ketidak akuratan dalam triage maka dapat berakibat merugikan pasien dan menurunkan kualitas pelayanan. Survey yang dilakukan oleh Chen, at al. (2010) terhadap 279 triage yang dikerjakan oleh perawat di Taiwan pada April sampai dengan Oktober 2006 menunjukkan bahwa rata-rata skor keakuratan perawat dalam melakukan triage adalah 5,62 poin dari total 10 poin. Data tersebut menunjukkan keakuratan triage yang dilakukan rendah, dimana $24,3 \%$ $(n=68)$ under triage dan $19,7 \%$ up triage.

Gerdtz \& Bucknall (2000) menyatakan secara umum terdapat dua faktor yang mempengaruhi akurasi pengambilan keputusan perawat dalam pelaksanaan triage.Faktor pertama adalah faktor internal yang menggambarkan tentang pengetahuan, pengalaman kerja dan pelatihan sedangkan faktor kedua merupakan faktor eksternal meliputi hal-hal yang berhubungan dengan lingkungan kerja, beban kerja, kondisi klinis dan riwayat klinis pasien. Penelitian lain yang dilakukan oleh Lusiana (2011) di RS Puri Indah Jakarta menunjukkan bahwa pengetahuan dan ketrampilan mempunyai hubungan dengan pelaksanaan triage,faktor lain adalah sikap yang dimiliki perawat juga mempengaruhi pelaksanaan triage.

Triage adalah proses pengambilan keputusan untuk memprioritaskan kebutuhan dan terapi pasien di IGD berdasarkan kegawatannya (Janssen, et al, 2011). Menurut Gerdtz \& Bucknall (2000) terdapat dua keputusan pada pengambilan keputusan perawat dalam proses triage.Pertama adalah keputusan triage primer yang berkaitan dengan penilaian awal, penentuan kategori keakutan, pemberian pertolongan pertama dan disposisi pasien. Kedua adalah keputusan triage sekunder berhubungan dengan inisiasi intervensi keperawatan untuk mempercepat tatalaksana kedaruratan dan memberikan kenyamanan pada pasien.

Pengambilan keputusan perawat dalam pelaksanaan triage dapat mempengaruhi hasil pelayanan terhadap pasien. Untuk dapat menggambarkan kemampuan pengambilan keputusan perawat dalam pelaksanaan triage di IGD, diperlukan suatu kajian yang lebih mendalam tentang berbagai faktor yang berperan dalam pengambilan keputusan perawat saat pelaksanaan triage.

Berdasarkan latar belakang di atas maka rumusan masalah dalam penelitian ini adalah adakah hubungan pengetahuan dengan akurasi pengambilan keputusan perawat dalam pelaksanaan triage di IGD RSUD Dr. Saiful Anwar Malang.

\section{METODE}

Penelitian ini menggunakan analitik korelasional dengan pendekatan crosssectional. Besar sampel menggunakan total sampling sebanyak 50 orang perawat IGD RSUD Dr. Saiful Anwar Malang yang masih bekerja aktif. Pengambilan data dengan kuesioner dan observasi terhadap subyek yang akan diteliti. Teknik Analisa data menggunakan univariat yang ditampilkan dalam bentuk distribusi frekuensi dan statistik parametrik bivariat dengan uji korelasi Pearson. 


\section{HASIL PENELITIAN}

Penelitian ini dilakukan pada pertengahan tanggal 15 April sampai 15Mei 2015 di IGD RSUD Dr. Saiful Anwar Malang. Pada penelitian ini terdapat 50 orang perawat dengan karakteristik subyek penelitian seperti terlihat pada

tabel 1.

Tabel 1. Karakteristik Sampel Penelitian

\begin{tabular}{lcccc}
\hline Karakteristik sampel & Sampel $(\mathbf{n}=\mathbf{5 0 )}$ & \multicolumn{1}{c}{ Persentase $\mathbf{( \% )}$} & \\
\hline Jenis kelamin: & & & & \\
Laki-laki & 22 & 54 & \\
Perempuan & 28 & & & \\
Tingkat Pendidikan: & & & 10 & \\
SPK & 5 & 74 & \\
D3 & 37 & & 16 & \\
S1 & 8 & Min & Max & SD \\
\hline Karakteristik sampel & Rata 2 (n=50) & 30 & 49 & $\pm 9,71$ \\
\hline \multicolumn{1}{r}{ Umur (tahun) } & 39,62 & & & \\
\hline
\end{tabular}

Tabel 2.Analisa Univariat Variabel Tabel 3. Hasil uji korelasi pengetahuan

\section{Penelitian}

\begin{tabular}{lcccc}
\hline $\begin{array}{l}\text { Karakteristik } \\
\text { sampel }\end{array}$ & $\begin{array}{c}\text { Rata } \\
\text { rata } \\
(\mathbf{n}=50)\end{array}$ & Min & Max & SD \\
\hline $\begin{array}{l}\text { Pengetahuan } \\
\text { Akurasi }\end{array}$ & 66 & 54 & 78 & \pm 12 \\
$\begin{array}{l}\text { pengambilan } \\
\text { keputusan } \\
\text { perawat }\end{array}$ & 87,52 & 77 & 98 & $\pm 10,891$ \\
\hline
\end{tabular}

Pada hasil Tabel 2 menunjukkan data pengetahuan subjek penelitian tersebardengan nilai rerata \pm standar deviasi adalah $66 \pm 12 \%$. Hal ini menjelaskan bahwa sampel penelitian yang terdiri dari 50 orang perawat yang bekerja di IGD RSUD Dr. Saiful Anwar Malangternyata memiliki rata-rata pengetahuan $66 \%$ dan tersebar sekitar interval antara 54\% sampai $78 \%$. Sedangkan pada data akurasi pengambilan keputusan perawat menunjukkan nilai rerata \pm standar deviasi adalah $87,52 \pm 10,891 \%$. Hal ini berarti bahwa akurasi pengambilan keputusan perawat yang bekerja di IGD RSUD Dr. Saiful Anwar Malang dalam pelaksanaan triage berkisar rata-rata $87,52 \%$ atau tersebar antara $76,63 \%$ sampai $98,41 \%$ atau 77\%-98\%. dengan akurasi pengambilan keputusan perawat

\begin{tabular}{ccc}
\hline Korelasi variabel & $\begin{array}{c}\text { Koefisien } \\
\text { korelasi } \\
\text { (r) }\end{array}$ & p-value \\
\hline $\begin{array}{l}\text { pengetahuan dengan } \\
\text { pengambilan akurasi } \\
\text { keputusan perawat }\end{array}$ & 0.565 & $0.000<\propto$ \\
\hline
\end{tabular}

Pada Tabel 3 menunjukkan bahwa ada hubunganyangbermakna antara pengetahuan dengan akurasi pengambilan keputusan perawat ( $p$ value $=0.000<\propto)$, dengan ditunjukkan tingkat keeratan hubungan yang cukup berarti. Hal ini ditunjukkan dengan nilai koefisien korelasi yaitu 0.565. Nilai positif 0.565menunjukkan ada hubungan yang positif atau hubungan yang seiring.

\section{PEMBAHASAN}

Hasil penelitian pada 50 orang perawat yang bekerja di IGD RSUD Dr. Saiful Anwar Malangternyata memiliki skor ratarata pengetahuan tentang triage $66 \%$ dan tersebar sekitar interval antara $54 \%$ sampai $78 \%$. Skor ini lebih besar dari hasil penelitian oleh Abbasi et. al. pada tahun 2004 yang telah diverifikasi dan mereka menemukan bahwa tingkat pengetahuan staf untuk triage dan pengobatan nuklir adalah 39,7\%. Mendukung penelitian ini, Ali at al, (2013) menyebutkan bahwa dari 
100 perawat di tiga rumah sakit pendidikan di Pakistan, 69\% perawat ditemukan dengan pengetahuan triage yang jelek. Respon yang benar dari keseluruhan kuisioner adalah 43,22\%.Hasil yang sama ditemukan di beberapa studi sebelumnya yang mendukung temuan ini. Sebuah studi yang disajikan oleh Marahaghi dan Roudbari (2011) melaporkan perawat belum cukup pengetahuan tentang triage rumah sakit, $39,94 \%$ dari tanggapan terhadap pertanyaan tingkat pengetahuan yang benar dalam studi mereka. Mereka menyimpulkan temuannya bahwa di IGD rumah sakit di Iran, perawat tidak dibekali dengan pengetahuan triage.

Tabel 3 menunjukkan bahwa terdapat hubunganyangbermakna antara pengetahuan dengan akurasi pengambilan keputusan perawat $(p$-value $=0.000<\propto)$ dengan ditunjukkan tingkat keeratan hubungan yang cukup berarti. Hal ini ditunjukkan dengan nilai koefisien korelasi 0.565 yangmenunjukkan ada hubungan yang positif atau hubungan yang seiring, Hal ini dapat diartikan bahwa bila terjadi peningkatan pengetahuan perawat maka akan meningkatkan akurasi pengambilan keputusan perawat dalam pelaksanaan triage. Hal ini sesuai dengan penelitian Fathoni (2010) yang menyebutkan bahwa terdapat korelasi positif antara keterampilan triagedenganpengetahuan, pelatihan dan pengalaman kerja.Mendukung penelitian ini juga Anderson at al. (2006), dan Considine, at al. (2007) menyatakan bahwa pengetahuan tentang triage merupakan faktor utama yang berhubungan dengan kemampuan triage.

Triage adalah tugas autonomi keperawatan. Tugas ini sangat penting untuk keselamatan pasien serta efisiensi pemberian pelayanan kegawatdaruratan. Keputusan klinis yang di buat oleh perawat triage memerlukan proses kongnitif yang kompleks, dimana perawat triage harus mampu menampilkan kemampuannya dalam berfikir kritis di tengah lingkungan yang memiliki informasi terbatas, tidak lengkap dan ambigu (Considine, 2007).

Pengetahuan tentang triage dapat diperoleh melalui beberapa cara baik formal maupun informal. Penelitian kualitatif yang dilakukan oleh Cone dan Murray (2002) menyatakan ada 5 tema yang didapatkan dari responden terkait persiapan untuk melakukan triage persiapan tersebut meliputi (1) membutuhkan pelatihan formal, (2) isu baru lulus, (3) memerlukan kursus sebelum melakukan triage, (4) perlu membaca literatur terbaru, dan (5) butuh dukungan dari rekan-rekan dan staf lainnya.

Pengetahuan tentang triage bisa didapatkan melalui suatu pelatihan. Namun belum ada standar baku pelatihan yang disyaratkan bagi perawat triage di Indonesia terkait dengan pelaksanaan triage. Adapun di Amerika dan secara internasional, Emergency Nurses Association(ENA) merekomendasikan sertifikasi pelatihan yang harus dimiliki oleh perawat triage termasuk Emergency Nursing Pediatric Course, TNCC, Advanced Cardiac Life Support, sertifikasi perawat emergensi dan telah mendapatkan pelatihan triage sedikitnya 4-8 jam (Dateo J dan Boston, 2013).Lebih lanjut College of Emergency Nursing Association(CENA) (2007) memberikan pedoman yang merupakan komponen inti dalam pelatihan triage bagi perawat yaitu sejarah, pengetahuan dan praktik triage, sistem triage yang dipakai, tugas dari perawat triage, keseluruhan sistem triage yang diterapkan misalnya Menggunakan triage SPACS atau Australian Triage Scale (ATS), Keterampilan komunikasi, survei primer dan sekunder, pengkajian dan pembuatan keputusan triage yang berkaitan dengan tipe kondisi pasien misalnya pasien trauma, pasien anak, obstetrik dan ginekologi. 
Considine (2007) menyatakan bahwa pengetahuan tentang triage telah dianggap sebagai salah satu faktor kunci yang mempengaruhi hasil pasien di IGD. Untuk perawat IGD, agar bisa bekerja secara efektif, mereka memerlukan pengetahuan yang mendalam dan keahlian klinis agar dapat memberikan perawatan di semua usia dan mampu mengelola dalam berbagai situasi seperti over crowded (Fry, 2004). Studi lain menunjukkan bahwa kualifikasi yang dibutuhkan untuk pekerjaan triage bervariasi, meskipun beberapa penulis menunjukkan bahwa melakukan triage memerlukan pengetahuan khusus (Goransson, 2005).

Sebuah studi oleh Andersson et al. (2006) juga menunjukkan bahwa triage yang efektif tergantung pada kualifikasi dan kualitas pribadi dari para perawat triage. Kualifikasi perawat triage adalah mereka yang sudah bekerja di IGD selama tidak kurang dari 6 bulan dan telah mendapatkan pelatihan TOC. Adapun kualitas pribadi menunjukkan kemampuan berpikir kritis dan mampu mengambil keputusan dengan tepat baik pada situasi tenang maupun pada situasi overcrowded.

Salah satu metode pembelajaran untuk meningkat pengetahuan dan skill dalam pengambilan keputusan triage adalah menggunakan simulasi skenario pasien. Metode pembelajaran ini dianggap cukup mendekatkan perawat dalam menghadapi situasi yang nyata.Namun, menurut Gerdz dan Bucknal (2001) kegagalan dapat terjadi saat diterapkan pada kasus yang sebenarnya.Kegagalan ini terjadi karena pada kasus nyata, terdapat faktorfaktorkontekstual dalam lingkungan tugas seperti keterbatasan waktu, beban stres dan interaksi sosial yang tidak dapat direplikasi seperti ketika keputusan simulasi dibuat.

\section{KETERBATASAN}

observasi terhadap akurasi pengambilan keputusan dalam pelaksanaan triage dilakukan satu kali pada setiap responden. Hal ini memungkinkan saat observasi dilakukan, kondisi fisik dan psikologi responden bisa dalam kondisi kurang sehat atapun dalam keadaan sehat.

\section{KESIMPULAN DAN SARAN}

Berdasarkan hasil penelitian, dapat disimpulkan bahwa ada hubungan pengetahuan, dengan akurasi pengambilan keputusan perawat dalam pelaksanaan triage.Diharapkan dari temuan ini, pihak rumah sakit dapat mengembangkan dan meningkatkan kemampuan perawat IGD dalam pengambilan keputusan triage. Peningkatan kemampuan triage dapat dilakukan melalui pendidikan, latihan scenario kasus dan pelatihan triage. Ketika perawat diberikan pelatihan, maka selanjutnya harus diikuti dengan evaluasi yang berkesinambungan sehingga dampak dan hasil pelatihan dapat diketahui.

\section{DAFTAR PUSTAKA}

Ali S at al. (2013) Knowledge of Triage Among Nurses in Emergency Units. Biomedica Vol. 29

Andersson, A. K., Omberg, M., \&Svedlund, M. (2006).Triage in the emergency department a qualitative study of the factors which nurses consider when making decisions.British Association of Critical Care Nurse, 11, 136-145

Chen, S.S., Chen, J.C., Ng, C.J., Chen, P.L., Lee, P.H., Chang, W.Y. (2008). Factors that Influence the Accuracy of Triage Nurses' Judgement in Emergency Departments. Emerg Med J ;27

$\begin{array}{rrrr}\text { College } \quad \text { of } & \text { Emergency } & \text { Nursing } \\ \text { Association. } & 2007 . & \text { Standard } \\ \text { Practise } & \text { Emergency } & \text { Nursing }\end{array}$


Specialist. College of Emergency

Nursing Association Australia

Cone, KJ.and Murray R. (2002). Characteristics, Insights, Decision

Making, and Preparation of ED

Triage Nurses.Journal of

EmergencyNursing, 28:5

Considine, J., M. Botti, and Thomas, S., (2007). Do Knowledge and Experience Have Specific Roles in Triage Decision-making? Academic emergency medicine, 14(8): p. $722-726$

Dateo J and Boston. (2013). What Factors Increase The Accuracy and Inter-Rater Reliability of The Emergency Severity Index Among Emergency Nurses In Triaging Adult Patients? Journal of Emergency Nursing Vol 39

Fathoni, Mukhamad. Hathairat Sangchan, Praneed Songwathana. 2010. Relationships between Triage Knowledge, Training, Working Experiences and Triage Skills among Emergency Nurses in East Java, Indonesia. Nurse Media Journal of Nursing, 3, 1, 2013, 511525511

Fry M. M.2004. Triage Nursing Practice in Australian Emergency Departments2002-2004: An ethnography. Department of Family andCommunity Health Nursing, Faculty of Nursing, University of Sydney,Sydney.

Gerdtz, M. and T. Bucknall.(2000). Australian Triage Nurses' Decision-Making and Scope of Practice. Australian Journal of Advanced Nursing 18(1): 24-33

Gilboy, N, Tanabe, P, Travers, D, Rosenau, A. (2005). Emergency Severity Index (ESI) A Triage Tool for Emergency Department Care Version 4 Implementation Handbook.agency for healthcare research and quality. Rockville

Goransson, K., Ehrenberg, A., Ehnfors, M., (2005). Triage in emergency departments: national survey. Journal of ClinicalNursing 14, 1067- 1074.

Janssen, M., Achterberg, T.V., Adriaansen, M., Kampshoff, C. S., Schalk, Groot, J.M.

Adherence to the guideline 'Triage in emergency departments': a survey of Dutch emergency departments. Journal of Clinical Nursing, 20, 2458-2468

Mirhaghi, A.H., Roudbari, M.A.(2011). Survey on Knowledge Level of the Nurses about Hospital Triage. I.J.C.C.N.; 3 (4): 167- 174.

National Center for Health Statistics (U.S.). (2004).National Hospital Ambulatory Medical Care Survey. Health Service Centers for Disease Control and publication.

Tsai, C., Rowe, B. H., Cydulka, R. K., \&Camargo,Carlos A.,JJ. (2009). ED visit volume and quality of care in acute exacerbations of chronic obstructive pulmonary disease. The American Journal of Emergency Medicine, 27(9), 1040-9.

Van der Wulp I, Van Baar ME \& Schrijvers AJP. (2008), Reliability and validity of the Manchester Triage System in a general emergency department patient population in the Netherlands: results of a simulation study. Emergency Medicine Journal

Van Gerven R, Delooz H \& Sermeus W. (2001), Systematic triage in the emergency department using the Australian National Triage Scale: a pilot project. European Journal of Emergency Medicine. 